\title{
ENTREVISTA \\ Políticas Públicas: uma interface sistêmica.
}

\author{
Entrevista concedida por Naomar Almeida Filho para a Revista \\ Tempus Actas de Saúde Coletiva, em $1^{\circ}$ de agosto de 2015.
}

Entrevistadores:

Oswaldo José BARBOSA

Marcus QUITO

\section{1ª PERGUNA: Para pensar as políticas públicas em saúde é preciso superar a fragmentação pela somática disciplinar, em âmbito acadêmico, mas como traduzir esta equação para o campo pragmático?}

Eu penso que existe uma questão prévia que é a natureza e produto dessa fragmentação. Muitos usam a metáfora das caixinhas, que se expressa de duas maneiras. Classicamente, as caixinhas são organizadas por campos disciplinares de pesquisa como a fisiologia, a parasitologia e todas as chamadas ciências básicas da Saúde. Para a organização do conhecimento sobre o corpo humano, essas caixinhas tiveram uma certa eficácia em um momento de grande relevância na história, correspondente ao nascimento da Clínica. A outra maneira, que é mais pragmática, faz o recorte do conhecimento pela organização do corpo ou, pelo menos, pela territorialização somática. Então temos estudos sistemáticos de pedaços do organismo como se fossem quase-disciplinas. A hepatologia do fígado, a pneumologia do pulmão, a nefrologia dos rins. Esses dois formatos de constituição das caixinhas são modos de organização do conhecimento. Um deles tem uma base epistemológica mais fundamentada, que considera a aplicação de disciplinas científicas; por exemplo, a citologia é uma aplicação da biologia celular ao organismo humano. O outro formato tem um estatuto epistemológico mais problemático, porque não faz nenhum sentido fragmentar em pedaços um organismo ou um corpo como estratégia para compreendê-lo. Mas, de todo modo, a formação dos sujeitos, que se tornarão agentes de intervenção sobre a saúde, tem se dado com base nesses recortes. A prática profissional desses sujeitos, formados dessa maneira, certamente se dará com base nesses modos de compreender a realidade por fragmentos ou recortes. São as famosas especialidades médicas. Algumas dessas especialidades, na verdade, são combinações de algumas dessas caixas que resultam em um terceiro recorte, no plano de mirada do conhecimento. Trata-se do corte entre o macro e o micro. Por exemplo, a anatomia patológica dando conta do micro em contraste com a anatomia do visível ou morfologia macroscópica. Esses modos de compreensão encontraram grandes problemas quando a questão principal deixou de ser organizar o conhecimento 
a partir de sujeitos que aprendiam em livros e aulas e sim formar sujeitos diretamente para o cuidado à saúde, na prática concreta do cuidar da saúde no mundo real. Com isso, a complexidade do ser humano não encontrava respaldo na pobreza dos fragmentos disciplinares ou nos recortes de territorialização somática ou mesmo no plano da ocorrência de fenômenos. Acrescento uma quarta questão que é o fato de que, no mundo ocidental, o cuidado em saúde se organizou com base em profissões hierarquizadas. É uma cena complexa e de difícil compreensão em sua totalidade.

A segunda parte da sua questão é como sair disso. Tem se avançado em muitos programas inovadores de formação no resto do mundo, como por exemplo no enfoque dos ciclos de vida, onde se problematiza o sujeito integral em diferentes momentos do seu desenvolvimento biológico, somático, psicológico. Cito os problemas de saúde-doença-cuidado que tem relação o desenvolvimento do ser humano em diferentes etapas, como, por exemplo, gestação e puerpério; infância e adolescência; a idade adulta que, na nossa sociedade, é muito referida à questão do trabalho e as diferenças de gênero; e a velhice, que nas sociedades ocidentais vem ganhando uma expressão muito grande pela transição demográfica, neste momento em que o contingente da população adulta e idosa suplanta a população juvenil e infantil. Esse recorte está presente nos programas de formação em saúde que, podemos dizer assim, são avançados em relação aos mais convencionais. Os cursos convencionais caracterizam-se pela fragmentação do objeto de conhecimento, e se organizam inclusive por uma hierarquia de profissões, resultando em formações exclusivas. Assim, se alguém ingressa em um curso de medicina, se torna acadêmico de medicina desde o primeiro dia. Obter essa atribuição qualifica todo o seu percurso de aprendizagem. Por mais convivência que exista ou articulação curricular que se produza artificialmente, não há interdisciplinaridade possível nessa formação. O modelo dos ciclos de vida permite e até promove a interdisciplinaridade e, no limite, a interprofissionalidade. Nesse modelo, é possível se ter competências definidas nas diferentes profissões em relação a saberes e práticas que se constituem de modo específico para cada uma dessas dimensões, tanto no processo de formação como também nas práticas. Devemos pensar mais em uma matriz de competências e menos numa grade curricular porque, quando dizemos algo sobre problemas de saúde e determinados cuidados, na verdade estamos embutindo uma série de estratégias de aproximação, definição e intervenção em um objeto de saberes e práticas. A primeira delas certamente é que chamamos genericamente de diagnóstico, ou seja, formas estruturadas de conhecer os problemas de saúde-enfermidadecuidado nos quatro ciclos de vida. Para além do diagnóstico, quer dizer, ações para reconhecer sinais e sintomas indicativos de uma certa identidade mórbida, esse reconhecimento implica também um conhecimento de mecanismos de ocorrência, ou seja, a etiologia das causas. Neste momento, é possível identificarmos, formas e modos de prevenção e controle como a segunda matriz de competências. Prevenção e controle são intervenções que se dirigem no mais das vezes a ambientes e situações, porém algumas se referem ao comportamento dos sujeitos como um segundo nível de referência.

E tem um outro nível - que corresponde a uma terceira matriz de competências - que é a intervenção. No caso de sociedades modernas como a nossa, com forte herança da matriz cultural 


\section{$311 / /$}

europeia, a intervenção é exclusividade de uma categoria profissional que ganhou esse monopólio na virada da revolução francesa, nos países latinos, e na revolução industrial nos países anglosaxões. Isso constitui um padrão respaldado politicamente e legislativamente na revolução francesa. Foi uma revolução feita por médicos, inclusive. Ao se consolidar esse padrão legislativo, obteve-se a exclusividade do chamado ato médico. Então formar alguém para ser médico é conceder uma chancela legal no que se refere a políticas de intervenção sobre os sujeitos. Essas intervenções se dão sobre o organismo e dentro do organismo, o que inclui a manipulação de moléculas e daí a discussão da farmacoterapia como monopólio dessa categoria profissional. Isso justificou, de alguma forma, a emergência de um modo exclusivo e separado de formação desses sujeitos especiais, em alguns países regulados por um processo legislativo quase autônomo em relação aos processos civis em geral. Por mais que outras categorias profissionais tenham se organizado desta maneira, os tribunais de prática profissional dos conselhos de medicina são os clássicos desse modelo. Esse modelo não admite uma constituição matricial que permita a interprofissionalidade na formação. Por outro lado, essa gradação da profundidade da intervenção permite organizar currículos e programas de formação em especialidades e isso nos diferentes modelos de formação com uma disposição bastante variada. Vejamos esse esboço: A organização indistinta em caixinhas de territorialidade somática somada à segmentação das ciências biológicas ou ciências naturais sobre o organismo humano, seguida de treinamento em práticas que já indicam a exclusividade de um certo saber ou profissão, onde alguns sujeitos mesmo em processo de formação e ainda não ungidos com a diplomação, são treinados para esses processos; e em paralelo, mas sem comunicação, classicamente em antagonismo com exclusão de categorias profissionais que são consideradas auxiliares nesse processo. Temos um enorme desafio: como construir um modelo de formação e, em seguida, um modelo de realização das práticas que, de alguma forma, conteste criticamente e, se possível, transgrida esse modo de organização? Isso porque esse modo de organização tem uma dificuldade muito grande de responder às necessidades da saúde da população. Não são os fígados ou os intestinos que adoecem e sim as pessoas. Ainda há uma questão muito complexa que é o desenvolvimento tecnológico baseado naquele modelo convencional. Como aplicar tudo isso para um modelo transformado? Essa é uma questão sequer formulada, na minha opinião.

\section{2 ${ }^{\text {a }}$ PERGUNTA: Como estabelecer uma interface sistêmica no tratamento das políticas públicas em saúde, tendo em vista a exagerada segregação setorial do aparato dos formuladores e implementadores da política?}

Paralelo à formulação da política pública de saúde e a segregação setorial, há a questão da implementação dessa política e a sua legitimação. Esses quatro pontos têm lógicas muito próprias e em antagonismo umas com as outras. A diferenciação entre quem formula a política e quem a implementa tem muito a ver com modelos de governança centralizados onde as políticas são implantadas de cima para baixo e em geral distanciadas de uma realidade concreta, ainda que isto seja conduzido por sujeitos com grande experiência e acúmulo na construção prática dessas experiências em contexto real. Mas mesmo assim, trata-se de uma situação problema, onde se monta o programa e esse programa se articula em políticas e práticas com muito pouco diálogo 
com a realidade existente. É claro que existe uma dificuldade grande na implantação de políticas dessa natureza e dessa forma, por motivos óbvios: simplesmente não se abriu espaço para uma construção participativa. Quando se abre esse espaço, o que não é simples, não é de modo algum trivial uma reformulação, porque essas políticas, para terem eficácia, em geral são operadas por dispositivos normativos e dispositivos dessa ordem trazem uma dinâmica de constituição que não tem permite diálogo. Um exemplo: quando o Congresso Nacional aprova uma lei, e se pode verificar, de imediato, que essa lei não corresponde a uma realidade concreta, quem vai fazer essa norma ineficaz retornar ao congresso para ser retificada? O processo de realização das práticas com base em legislação é um processo linear e depende de dispositivos jurídicos embasados naquilo que Foucault propunha como foco do poder sistêmico e centralizado: o Estado. É assim que os Estados modernos se constituem e se organizam.

No Brasil temos um elemento adicional que contribui para piorar esse processo, que é o não reconhecimento da própria sociedade nas matrizes jurídicas do país. É como se não existisse social no Brasil, país dividido entre Estado e Mercado, sem comunidade, sociedade ou governo. Esta situação absurda termina fazendo com que o governo se confunda com o Estado e a sociedade com o mercado. Essa situação produz invisibilidade jurídica do que nos outros países é chamado de terceiro setor, que, entre nós, é indistinto ou inexistente juridicamente. Todo o terceiro setor no Brasil é de direito privado e parcamente se distingue do setor empresarial constituído na relação entre pessoas jurídicas de direito privado. A constituição de entes jurídicos formados por cidadãos ou cidadãs com objetivos socialmente justos é tratada da mesma maneira que a organização de empreendimentos visando ao lucro, no plano da legalidade, ou uma quadrilha montada para corrupção ou outra prática ilícita qualquer, no plano da ilegalidade. Eu acredito que vamos continuar a ter muita dificuldade de interação do setor público com a sociedade se continuarmos com um sistema que não reconhece que existe a comunidade e a sociedade.

A operação de sistemas de gestão pública na área da saúde enfrenta dificuldades e problemáticas adicionais, pois o modo de constituição do estado brasileiro produz uma burocracia não no sentido weberiano. Assim, princípios constitucionais são definidos e impostos porque são legais; e não podem deixar de ser seguidos mesmo que resultem em ineficiência geral do sistema. É lamentável que esse sistema seja gerido prioritariamente pelo cumprimento da norma independentemente de resultados e não pela necessidade e direito de uo serviço público bem prestado ou mesmo pela demanda da sociedade que precisa desse direito. Além desses, há mais dois níveis na compreensão dessa problemática. O terceiro nível é a questão da operacionalização de um sistema universal de saúde de fato sofrer com as deficiências estruturais do Estado brasileiro. Este é um enorme paradoxo. Entendo que esse paradoxo na saúde é muito semelhante ao que acontece também na educação, que é constitucionalmente considerada um direito público mas que tem natureza e grau de privatização muito grande, inclusive pelo fato de que não se reconhece que é possível ter formas sociais não estatais e não privadas que potencialmente seriam capazes de ajudar o Estado a dar conta da garantia desse direito. E o quarto nível compreende o tema da legitimação dos sistemas públicos de saúde e de educação. Isso passa pela compreensão da sociedade como um todo sobre 


\section{$313 / /$}

o valor dos serviços públicos em uma sociedade que se nega como tal e se define como mercado. Aqui e agora, tudo passa a ter valor de troca. Temos na Saúde Coletiva brasileira um discurso muito firme politicamente contrário a pensar a saúde como mercadoria numa sociedade em que, do ponto de vista jurídico, todos os bens e serviços só podem ser pensados como mercadoria. No contexto brasileiro atual, os serviços públicos têm um valor atribuído pelo mercado ou pelo Estado, mas o Estado abdica de cumprir sua missão de produzir serviços públicos de qualidade, como o cuidado à saúde, por não demonstrar eficiência e capacidade de produção possível e termina por renunciar ao seu papel em favor do mercado, contratando-o. O Estado brasileiro renuncia a prestar serviços educacionais e assistenciais de qualidade, reconhecendo como isenção tributária justa gastos com educação e com saúde. E o faz dizendo que cada cidadão pode, por iniciativa própria, comprar tais serviços sendo que o Estado faz o devido ou indevido ressarcimento pela renúncia na tributação. Que eu saiba, isso só acontece no Brasil e vejo esse tema muito pouco discutido no cenário nacional. Enfim, eu assinalaria esses pontos, específicos da realidade brasileira, para responder sua complexa e oportuna questão.

\section{$3^{\text {a }}$ PERGUNTA: A garantia da postura interdisciplinar e intersetorial para a condução} das políticas públicas de saúde e os problemas da complexidade social, perpassa por uma formação acadêmica singular. Quais as competências que o futuro profissional da saúde coletiva deve desenvolver?

Para responder essa questão é preciso uma abordagem mais ampla acerca da formação do profissional de saúde em geral. Hoje acontece no mundo uma transição muito rápida, não há condição de mensurar os efeitos da massividade da tecnologia. Existe uma tecnologia de uso cada vez mais corriqueiro, com equipamentos e processos que têm grau de complexidade muito grande e que não mais são geridos na lógica de valor baseado em tempo e energia e sim valor baseado em conhecimento incorporado. De fato, a constituição de valor das mercadorias cada vez menos define-se classicamente por uma base físico dos produtos: matéria prima, insumos materiais, etc., mas também tempo usado na produção, numa definição cumulativa de carga horária. Hoje, processos automatizados podem ainda tomar algum tempo, mas não mais tempo que o trabalho humano. O limite do trabalho humano é o limite do corpo, mas o limite da automação não é mais o limite físico da velocidade e da fadiga. É possível ter um robô produzindo no limite do seu programa, e ainda sem nenhum problema multiplicar por 20 as unidades do processo. O que se torna o elemento mais fundamental desse processo de produção é o conhecimento embutido nessa tecnologia dita embarcada, e também no mecanismo de controle dessas máquinas que é a programação. A programação se torna então um elemento a ser agregado à constituição do valor que não usa mais as mesmas regras de entendimento desse valor que eram válidas no âmbito da produção na época clássica do capitalismo industrial.

No capítulo $\mathrm{V}$ de $\mathrm{O}$ Capital se analisa a decomposição do processo de trabalho com base no processo de produção definido desta maneira. Mas considere neste momento uma maquininha como este telefone celular. Na constituição de seu valor e daí seu preço, o custo do material empregado 
é mínimo. O tempo utilizado para fazer essa maquininha é pouco também, até porque todo o processo miniaturizado está praticamente fora do alcance da capacidade manual humana e por isso é automatizado. É, portanto, impossível de ser feito manualmente. O que eu pago por este aparelho é muito mais a inteligência nele incorporada e essa inteligência pode ser reproduzida sem insumos físicos, de modo que para cada nova máquina esse valor é replicado sem custos. Esta forma de agregação do valor à mercadoria é totalmente distinta da forma clássica porque o processador que opera este equipamento custou muito pouco do ponto de vista da sua materialidade porque é minúsculo e foi fabricado por quase total automação e seu sistema operacional e aplicativos não têm materialidade alguma. Estamos neste momento, neste mundo, em uma transição da qual não sabemos os efeitos, porque começa com velocidade, intensidade e alcance muito grandes, trazendo inclusive um componente social inesperado: a desigualdade de acesso dos sujeitos aos usos e benefícios de produtos dessa natureza que também não dá para ser medida pelos mesmos padrões e parâmetros do modo clássico de produção.

As consequências disso para a saúde são inúmeras, desde novas patologias até novas formas de lidar com as velhas patologias. No tema da formação dos profissionais de saúde, é crucial a eficiência das intervenções, que de algum modo se contrapõe à ideia de competência como capacidade de resolução. Podemos considerar que existe uma competência que não resolve. Tem-se às vezes eficiência para produzir efeitos sobre a saúde, com algum grau de eficácia mas efetividade muito reduzida. Agora, mais que antes, dispomos de tecnologia para a resolução de muito problemas de saúde mas não os resolvemos por razões sociais e políticas. De fato precisamos pensar o tema da tecnologia em bases além da vanguarda experimental, que se limita à mera eficácia em situação ideal de aplicação tecnológica. Para a saúde coletiva esta é uma questão crucial, e até muito estudada. O principal desdobramento dessa questão, para o que nos interessa, é que os modos mais convencionais de incorporação do conhecimento mediante processos educacionais para desenvolvimento de competências e habilidades com base em conteúdos na minha opinião estão superados. Eu não preciso mais decorar quais são as inserções de ligamentos anteriores e posteriores ou que nomes têm os buracos dos ossos, os fatídicos forâmens; isto é hoje virtualmente inútil, mas o sistema de formação continua exercitando esse modelo na maioria dos casos. Em vez de se desenvolver modos de compreensão de modelos e resolução de problemas, ainda se promove memorização e aprendizado de pautas fixas de intervenção, numa perspectiva clínica consolidada em suas diretrizes metodológicas no início do Século XIX. A competência de dominar essas pautas fixas de intervenção pode ser realizada automatizando processos para memorização de informação, bastando para isso apenas saber como acionar mecanismos tecnológicos de acesso à informação. Alguns deles (e a tecnologia também propiciou isso), são tão baratos que não faz mais nenhum sentido se gastar caros neuroespaços de armazenagem para memorizar e de processamento mental para compreender. Este momento exige uma pedagogia toda nova, completamente distinta daquela que formou a geração anterior, a nossa geração.

Eu vejo uma interface muito grande entre esta questão e a problemática mais crucial deste momento nos contextos da educação e da saúde. Na saúde e na educação, ressalta a força dos 


\section{$315 / /$}

processos coletivos. Portanto também eu agregaria esse tema às competências do profissional de saúde do futuro: saber fazer coisas juntos. Mas a sinergia do coletivo é muito falada mas de fato pouco usada. Os modelos de ensino-aprendizagem dos profissionais de saúde continuam extremamente individualizados, o que ocorre também na produção do cuidado. Quer dizer, por mais que se discuta e se formule como necessidade e modelo ideal, a prática de serviços de saúde continua baseada no contato singular clínico-paciente. Todo um aparato organizacional, complexo, caro e sofisticado, resulta na individualização de um ato. Esse ato costuma se fundar sobre uma ética do individuo singular e, na minha opinião, nada é mais anacrônico hoje que uma ética da singularidade e do individualismo. Certamente que toda essa avassaladora explosão das redes sociais, criando mesmo mundos virtuais, tem consequências não somente sobre processos patológicos, mas também sobre modos de lidar com a constituição da saúde dos sujeitos e evidentemente sobre os modos de formação dos operadores tecnológicos, intelectuais e gerenciais dessas práticas.

Eu penso que a formação de profissionais da saúde coletiva deve incluir uma competência tecnológica mais potente e crítica, porque senão nós teremos o mais perverso uso do conceito de equipe que é alguém ser detentor de um modo de fazer que se torna poder na relação com os outros. E aí o empobrecimento da prática é inevitável. Nesse sentido, um domínio mínimo sobre fundamentos da lógica de programação já deveria fazer parte da necessidade dos sujeitos que se apresentam à formação. Por exemplo: o conceito de algoritmo; ninguém precisa ser um grande programador se entender o conceito de algoritmo e aplicar essa compreensão à crítica dos processos de prestação dos serviços, dos procedimentos de intervenção, do uso de equipamentos, bem como dos próprios processos de formação. Se a formação tecnológica não é predominante na saúde coletiva, temos uma vantagem sobre os demais segmentos da formação do profissional de saúde porque pelo menos já estamos consciente desse debate, que é a análise da tecnologia nos seus aspectos principalmente de custo-efetividade. Temos até amplas condições de formular criticamente e de modo ainda mais aprofundado sobre essa questão.

Para fechar, e para responder diretamente à questão formulada, diria que o profissional da saúde do futuro deve ser capaz de aplicar modos matriciais de organização e articulação do conhecimento desde sua prática da formação. Isso implica conhecer e praticar a interdisciplinaridade mas transgredir com os modos antiquados de formação e de prática profissional, embora respeitando as regras externas do processo de formação, permitindo uma compreensão mais clara do papel da tecnologia na formação para que se formem sujeitos que possam ser críticos na aplicação e na incorporação do conhecimento. Conhecimento não necessariamente internalizado, ou seja, dominado pelos sujeitos com uma base de memorização; e sim com domínio dos processos de acesso e com capacidade de lidar com as aplicações e implicações desse conhecimento. E para isso, os profissionais de saúde de hoje precisam ter uma compreensão mais ampla das bases bioecológicas da saúde-enfermidade, entendendo o ser humano como parte de um ecossistema rico, delicado e complexo, bem como dos processos e fatores culturais, sociais e políticos de determinação da situação de saúde e dos sistemas e serviços. Além disso, juntamente com uma consciência mais clara e mais crítica da implicação social dos processos de produção de cuidado, dominando as formas de aplicação das 
$316 / /$

tecnologias desenvolvidas para as intervenções nos corpos sociais, individuais e coletivos, para a promoção da saúde; e tudo isso agregado a uma competência de uso efetivo dos saberes, práticas e técnicas. Trata-se enfim da competência de como fazer aplicação da tecnologia no máximo da sua eficácia e eficiência, fazendo dessa eficácia, efetividade e transformação sustentável. Este é o nosso maior desafio nos modelos de formação em saúde, é o que penso. 